\title{
Chemical States of Water Molecules Distributed inside a Proton Exchange Membrane of a Running Fuel Cell Studied by Operando Coherent anti-Stokes Raman Scattering Spectroscopy
}

Hiromichi Nishiyama, ${ }^{\dagger,+}$ Shogo Takamuku, ${ }^{\dagger}$ Katsuhiko Oshikawa, ${ }^{\dagger}$ Sebastian Lacher, ${ }^{\dagger}$ Akihiro Iiyama, ${ }^{\S}$ Junji Inukai ${ }^{\S, \pi, *}$

${ }^{\dagger}$ Corporate Research, Asia Pacific, District Japan, Bosch Corporation, 3-6-7 Shibuya, Shibuya-ku, Tokyo, Japan

Integrated Graduate School of Medicine, Engineering, and Agricultural Sciences, University of Yamanashi, 4-3-11 Takeda, Kofu, Yamanashi, Japan

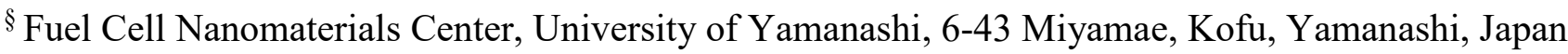

"Clean Energy Research Center, University of Yamanashi, 4-3-11 Takeda, Kofu, Yamanashi, Japan

${ }^{*}$ Corresponding author

E-mail: jinukai@yamanashi.ac.jp (J. Inukai)

Tel.: +81 552208185

Fax: +81552208185 


\section{EXPERIMENTAL SECTION}

\section{Criteria for equilibration}

We have defined the equilibrium criteria in terms of the cell voltage. Every minute, the cell voltage was measured for $10 \mathrm{~s}$ until the change in voltage became less than $0.001 \mathrm{~V}$, or the detection limit. In all experiments, 3 hours were needed for the equilibration.

\section{Measurement of the membrane thickness}

The membrane thickness was measured from the range, in which the CARS signal was detected; the measurement locations were moved from the cathode to the anode by $0.5 \mu \mathrm{m}$ in depth. Figure $\mathrm{S} 1 \mathrm{shows}$ the depth profile of $A_{\mathrm{O}-\mathrm{H}}$ in a Nafion membrane at $80{ }^{\circ} \mathrm{C}$ and $60 \% \mathrm{RH}$ under $\mathrm{N}_{2}$ flow. The location at which $A_{\mathrm{O}-\mathrm{H}}$ began to increase was considered as $0 \mu \mathrm{m}$. Molecular vibration derived from the membrane was detected in the range of $0-20.5 \mu \mathrm{m}$ under the condition.

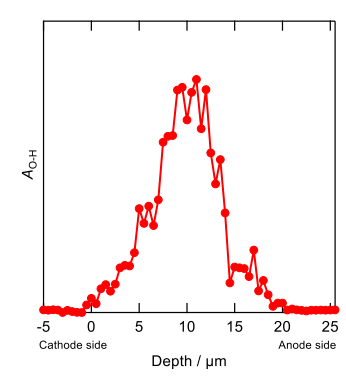

Figure S1 Depth profile of $\mathrm{A}_{\mathrm{O}-\mathrm{H}}$ in Nafion membrane at $80{ }^{\circ} \mathrm{C}$ and $60 \%$ RH under $\mathrm{N}_{2}$ flow. 


\section{Calculation of focal size}

The diameter and depth of the focal spot were calculated from the specifications of the objective lens and the laser diameter. The diameter of focal spot was calculated as follows:

$$
\text { Spot diameter }=\frac{4 \times \lambda \times f}{\pi \times d}
$$

where, $\lambda, f, d$ are the wavelength of the laser light $(532 \mathrm{~nm})$, focal length of the objective lens $(10.6 \mathrm{~mm})$, and diameter of the laser beam $(2.0 \mathrm{~mm})$, respectively. The diameter of the focal spot was calculated as $3.6 \mathrm{~nm}$.

The depth of the focal spot was calculated as follows:

$$
\text { Focal depth }=\frac{\lambda}{2 \times(N . A)^{2}}
$$

where (N.A) is the numerical aperture of the objective lens (0.5). The focal depth was calculated as $1.06 \mu \mathrm{m}$. 


\section{RESULTS AND DISCUSSION}

\section{CARS spectra of Nafion at various RHs under humidified $\mathbf{N}_{2}$}

The CARS spectrum was recorded every $5.0 \mu \mathrm{m}$ in depth in the Nafion membrane at $80{ }^{\circ} \mathrm{C}$ under an $\mathrm{N}_{2}$ flow humidified at 40,60 , and $80 \%$ RH. $A_{\mathrm{O}-\mathrm{H}} / A_{\mathrm{C}-\mathrm{F}}$ was calculated for all spectra. Figure $\mathrm{S} 2$ shows the depth profile of $A_{\mathrm{O}-\mathrm{H}} / A_{\mathrm{C}-\mathrm{F}} . A_{\mathrm{O}-\mathrm{H}} / A_{\mathrm{C}-\mathrm{F}}$ was almost constant regardless of the membrane depth, reflecting the uniform water distribution inside the PEM under the humidified $\mathrm{N}_{2}$ atmosphere, whereas $A_{\mathrm{O}-\mathrm{H}} / A_{\mathrm{C}-\mathrm{F}}$ increased with increasing $\mathrm{RH}$, corresponding to the increase in water content inside the membrane.

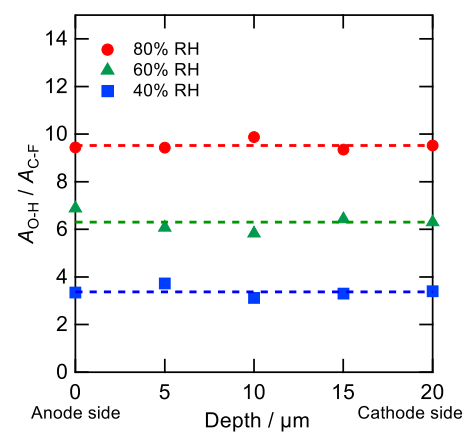

Figure S2 Depth profiles of $\mathrm{A}_{\mathrm{O}-\mathrm{H}} / \mathrm{A}_{\mathrm{C}-\mathrm{F}}$ in Nafion membrane at $40,60,80 \% \mathrm{RH}$ at $80{ }^{\circ} \mathrm{C}$. 


\section{Calibration curve for quantification of $\lambda$ from spectra}

To quantify the $\lambda$ value from the spectral data, a calibration curve of $\lambda$ vs. $A_{\mathrm{O}-\mathrm{H}} / A_{\mathrm{C}-\mathrm{F}}$ was created by removing the $\mathrm{RH}$ term from the data of $A_{\mathrm{O}-\mathrm{H}} / A_{\mathrm{C}-\mathrm{F}} \mathrm{vs}$. $\mathrm{RH}$ and of $\lambda$ vs. $\mathrm{RH}$ (values are reported in reference 1 ). The $\lambda$ value was proportional to $A_{\mathrm{O}-\mathrm{H}} / A_{\mathrm{C}-\mathrm{F}}$, and the $\mathrm{R}^{2}$ value was 0.9998 . During the humidification or the power generation, the $\mathrm{CF}$ stretching vibration did not change, even increased the number of water molecules contributing to the increase in $\mathrm{OH}$ stretching vibration. Accordingly, a calibration curve of $\lambda$ vs. $A_{\mathrm{O}-\mathrm{H}} / A_{\mathrm{C}-\mathrm{F}}$ was obtained by measuring those ratios with known lambdas.

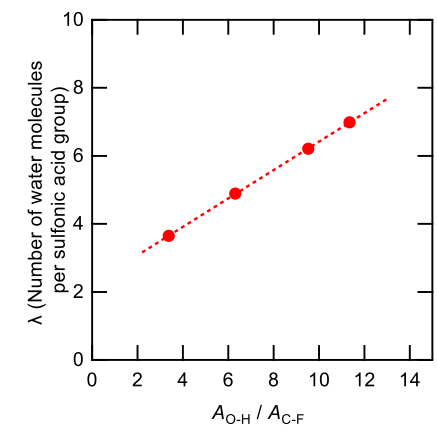

Figure S3 $\lambda$ vs. $\mathrm{A}_{\mathrm{O}-\mathrm{H}} / \mathrm{A}_{\mathrm{C}-\mathrm{F}}$ at $80^{\circ} \mathrm{C}$. 


\section{Deconvolution with 4-peak fitting}

We attempted an analysis with a 4-peak fitting according to previous studies. ${ }^{2-4}$ Figure S4 shows the $\lambda$ values of different types of water in a Nafion membrane as a function of relative humidity obtained by the 4-peak fitting. In terms of fitting accuracy, the probability value was 0.95 or more, but the result did not satisfy the electrical neutrality.

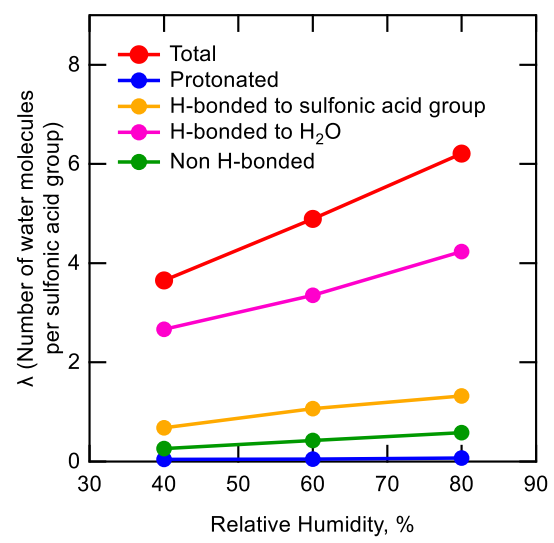

Figure S4 $\lambda$ of different types of water in Nafion membrane as a function of relative humidity calculated based on four-peak deconvolution of $\mathrm{O}-\mathrm{H}$ stretching band as in the manner previously proposed. 


\section{Depth profiles of $\lambda$ values in Nafion membrane during the cell operation}

Figure S5 shows CARS spectra of Nafion during the cell operation at 0.5 and $0.1 \mathrm{~A} \mathrm{~cm}^{-2}$ at $80{ }^{\circ} \mathrm{C}$ and

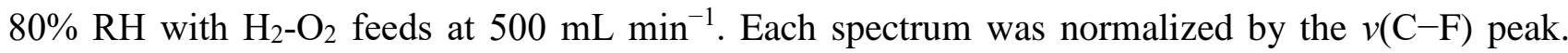
Similar to Fig. 6 in the manuscript, the area of the $v(\mathrm{O}-\mathrm{H})$ peak decreased as the measurement position moved to the anode, corresponding to the decrease in the amount of water from the cathode to the anode. Figure S6 shows the depth profiles of $\lambda$ in Nafion membrane during cell operation calculated from the spectra and the calibration curve (Fig. S3). The $\lambda$ values obtained during cell operation were larger than that at $0 \mathrm{~A} \mathrm{~cm}^{-2}$ and increased from the anode to the cathode. With increasing the current density, $\lambda$ increased at all measurement locations due to the water generation at the cathode.
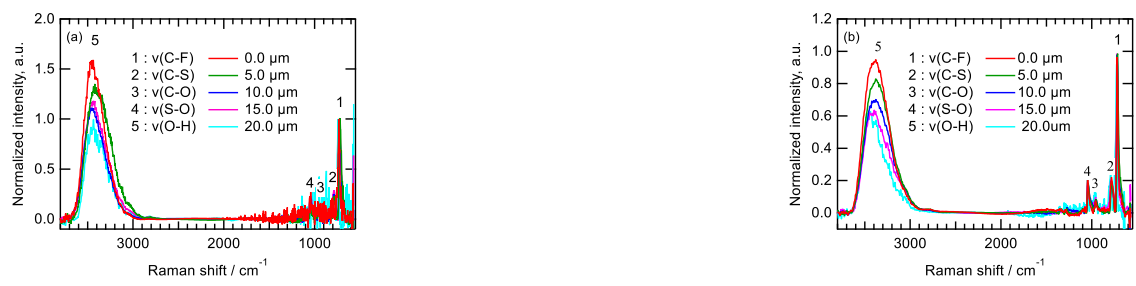

Figure S5 CARS spectra of Nafion during cell operation at 0.5 (a) and $0.1 \mathrm{~A} \mathrm{~cm}^{-2}$ (b) at $80^{\circ} \mathrm{C}$ and $80 \% \mathrm{RH}$ with $\mathrm{H}_{2}-\mathrm{O}_{2}$ feed at $500 \mathrm{~mL} \mathrm{~min}^{-1}$.

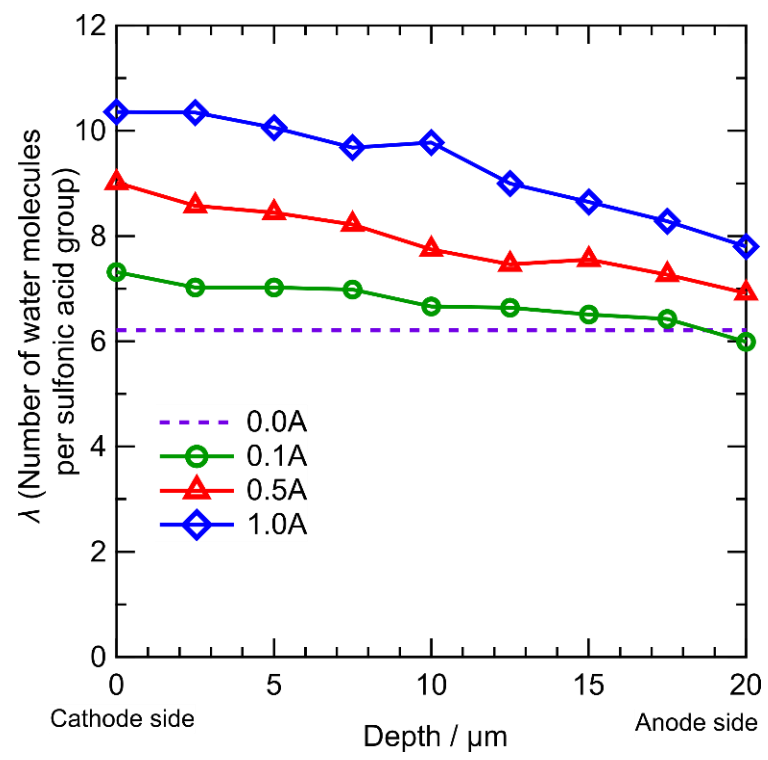

Figure S6 Depth profiles of $\lambda$ in Nafion membrane during cell operation at $0-1.0$ A cm ${ }^{-2}$ with $\mathrm{H}_{2}-\mathrm{O}_{2}$ feed at $500 \mathrm{~mL} \mathrm{~min}^{-1}$ at $80{ }^{\circ} \mathrm{C}$ and $80 \% \mathrm{RH}$. 


\section{Derivation of Equation (3)}

Equation (3) in the manuscript was derived as in the following procedure.

The $\lambda$ value is defined as:

$$
\lambda=\frac{\text { Number of water molecules }}{\text { Nubber of sulfonic acid group }}
$$

The number of water molecules and sulfonic acid are described as follows:

$$
\lambda=\frac{\frac{V_{\mathrm{H}_{2} \mathrm{O}} \times \rho_{W}}{M_{\mathrm{H}_{2} \mathrm{O}}}}{\frac{V_{\text {polymer }} \times \rho_{\text {polymer }}}{E W}}
$$

where $\mathrm{V}, \rho, \mathrm{M}$, and $\mathrm{EW}$ are volume, density, molecular weight, and equivalent weight, respectively.

In summary, $\lambda$ is described as below. Note that $\mathrm{V}_{\text {polymer }}$ is the value under dry condition.

$$
\lambda=\frac{V_{\mathrm{H}_{2} \mathrm{O}} \times \rho_{\mathrm{H}_{2} \mathrm{O}} \times E W}{V_{\text {polymer }} \times \rho_{\text {polymer }} \times M_{\mathrm{H}_{2} \mathrm{O}}}
$$

Here, with the volume fraction of water, $\Phi$, and the total volume of the system, $\mathrm{V}, \lambda$ is described as

follows:

$$
\begin{aligned}
\lambda & =\frac{\Phi \times \rho_{\mathrm{H}_{2} \mathrm{O}} \times E W}{(1-\Phi) \times \rho_{\text {polymer }} \times M_{\mathrm{H}_{2} \mathrm{O}}} \\
& \because V_{\mathrm{H}_{2} \mathrm{O}}=V \times \Phi \text { and } V_{\text {polymer }}=V \times(1-\Phi)
\end{aligned}
$$

From Equation (4), the following equation is obtained.

$$
\Phi=\frac{\lambda \times \rho_{\text {polymer }} \times \mathrm{M}_{\mathrm{H}_{2} \mathrm{O}}}{\rho_{\mathrm{H}_{2} \mathrm{O}} \times \mathrm{EW}+\lambda \times \rho_{\text {polymer }} \times \mathrm{M}_{\mathrm{H}_{2} \mathrm{O}}}
$$




\section{REFERENCES}

1. Hara, M.; Inukai, J.; Bae, B.; Hoshi, T.; Miyatake, K.; Uchida, M.; Uchida, H.; Watanabe, M., Micro-Raman Study on Water Distribution inside a Nafion Membrane During Operation of Polymer Electrolyte Fuel Cell. Electrochim. Acta 2012, 82, 277-283.

2. Ferrari, M. C.; Catalano, J.; Baschetti, M. G.; De Angelis, M. G.; Sarti, G. C., Ftir-Atr Study of Water Distribution in a Short-Side-Chain Pfsi Membrane. Macromolecules 2012, 45, 1901-1912.

3. Hofmann, D. W.; Kuleshova, L.; D'Aguanno, B.; Di Noto, V.; Negro, E.; Conti, F.; Vittadello, M., Investigation of Water Structure in Nafion Membranes by Infrared Spectroscopy and Molecular Dynamics Simulation. J. Phys. Chem. B 2009, 113, 632-639.

4. Barique, M. A.; Tsuchida, E.; Ohira, A.; Tashiro, K., Effect of Elevated Temperatures on the States of Water and Their Correlation with the Proton Conductivity of Nafion. ACS Omega 2018, 3, 349-360. 